Obere Extremität 2020 · 15:251-259 https://doi.org/10.1007/s11678-020-00605-w Received: 12 August 2020

Accepted: 15 September 2020

Published online: 9 October 2020

(c) The Author(s) 2020

A fully functional upper extremity depends on the stability of the elbow joint. Fractures can compromise this stability and radial head fractures account for $30 \%$ of elbow fractures [1]. The incidence of radial head fractures has a bimodal pattern, with a peak at 37 years for men and 52 for women (• Fig. 1; [1-3]). The mechanism of injury is most commonly a fall onto an outstretched hand; however, any mechanism applying an axial force along the long axis of the radius can be causative. Women tend to sustain lower-energy injuries, whereas males more often sustain higher-energy injuries [2]. Disruption of the important ligamentous stabilizers of the elbow joint are also common with radial head fractures.

\section{》) A fully functional upper extremity depends on the stability of the elbow joint}

Although extensively studied, treatment of radial head fractures remains controversial particularly in younger patients with more severe injuries [4]. Pain, stiffness, and limitations in range of motion (ROM) are associated with both operative and nonoperative treatment. As a result, these injuries can lead to significant disability in young, active patients if not managed appropriately.

\section{Anatomy}

The elbow joint is made up of three articulations: ulnohumeral, radiocapitellar, and proximal radioulnar. Overall, $60 \%$ of the load transferred across the elbow joint is transmitted through the radiocapitellar joint [1]. The radial head

\author{
Christopher G. Larsen' • Michael J. Fitzgerald · Andrew S. Greenberg ${ }^{1,2}$ \\ ' Department of Orthopaedic Surgery, Northwell Health, New Hyde Park, USA \\ ${ }^{2}$ Orthopaedic Associates of Manhasset, Manhasset, USA
}

\title{
Radial head fractures in young, active patients
}

is a secondary restraint to valgus forces on the elbow and provides longitudinal stability, preventing proximal migration of the radius. The concave radial head articulates with the convex capitellum and the medial rim of the radial head articulates with the lesser sigmoid notch of the ulna.

Articular cartilage covers the radial head in a 280-degree arc with the remaining 80 degrees representing the nonarticular posterolateral side. This nonarticular "safe zone" can be identified as the region between two longitudinal lines drawn from the radial styloid and Lister's tubercle $[1,3]$. When using plate fixation, the plate should be placed in this safe zone to prevent impingement on the ulna during forearm pronation and supination.

Given that ligamentous injury is common with radial head fractures, understanding the ligaments of the elbow and their contributions to stability is necessary for successful outcomes. On the lateral side of the elbow the lateral ulnar collateral ligament (LUCL) is the primary restraint to varus and external rotation forces and prevents posterolateral rotatory instability. Similarly, on the medial side the anterior bundle of the medial collateral ligament (MCL) is the primary restraint to valgus forces on the elbow, the posterior bundle, and the transverse bundle $[1,5]$.

\section{Patient presentation and evaluation}

Young, active patients with radial head fractures most commonly present after a high-energy fall onto an outstretched arm with the forearm in pronation and the elbow in slight flexion. Associated injuries occur in up to $92 \%$ of radial head fractures [6]. Rhyou et al. showed that isolated radial head fractures are often associated with MCL injuries, while combined radial head and coronoid fractures are more likely to accompany LCL injuries [5]. As such, a thorough examination of the injured upper extremity must be performed. Elbow ROM in terms of flexion, extension, pronation, and supination should be evaluated looking for any mechanical blocks to motion. Hematoma in the radiocapitellar joint can be aspirated and local anesthetic may be injected to alleviate pain and facilitate assessment of whether ROM limitations are due to a true mechanical block. Elbow stability should be evaluated with varus and valgus stresses, as well as examined for posterolateral rotatory instability. That said, discomfort despite attempted aspirations and injections will frequently limit the accuracy of the physical examination in the clinic. Instability is often identified intraoperatively, and the surgeon must be prepared to perform ligamentous repair, reconstruction, or in some cases place a dynamic external fixator.

\section{Imaging}

Initial imaging studies to assess for a radial head fracture include anteroposterior (AP), lateral, oblique, and radiocapitellar (Greenspan) radiographs of the elbow (• Fig. 2). If no displaced fracture is present, an anterior or posterior fat pad sign seen on a lateral radiograph can indicate a non-displaced radial head fracture [7]. Additional radiographs of the ipsilateral extremity as well as of other ex- 


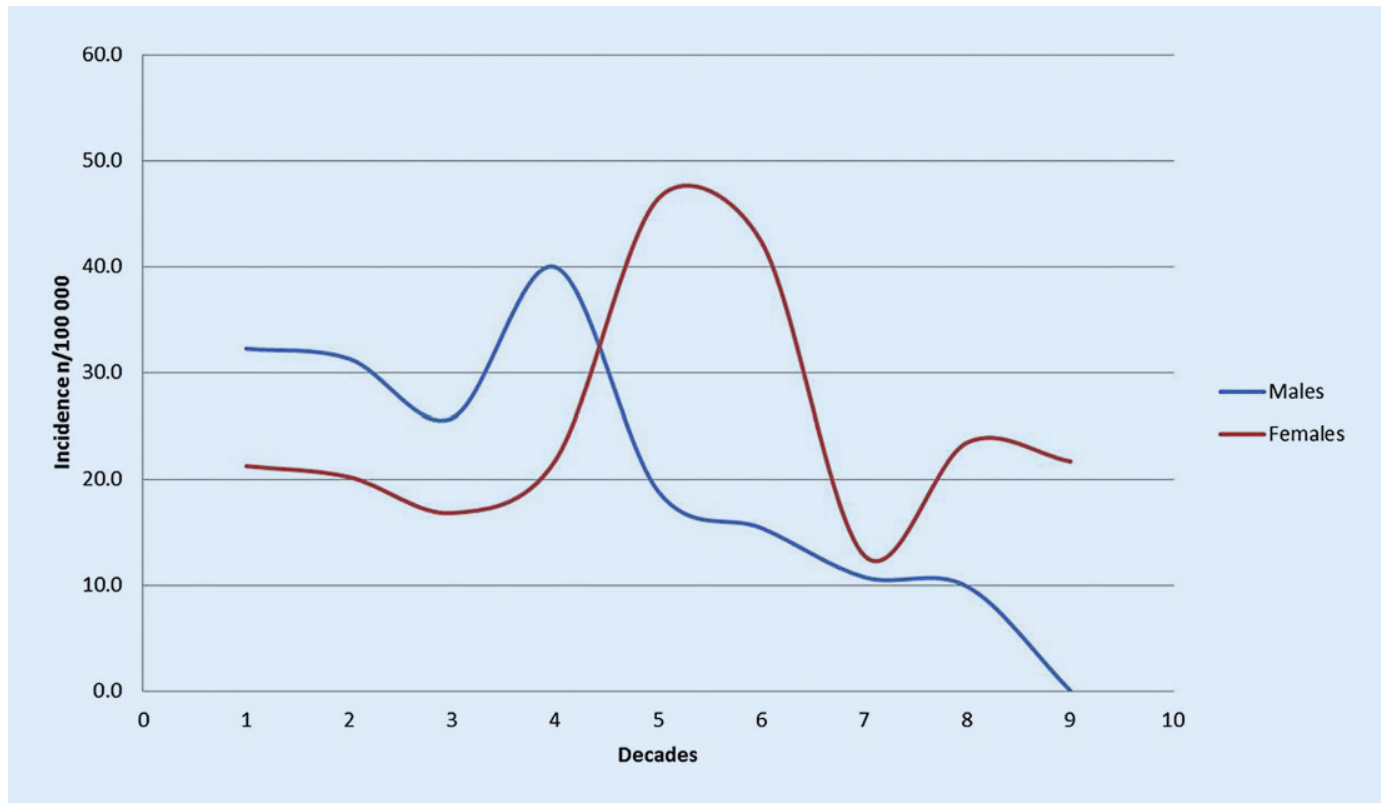

Fig. $1<$ Incidence of radial head fractures. The age of peak incidence for radial head fractures for males (blue line) and females (red line). (With kind permission from [2])
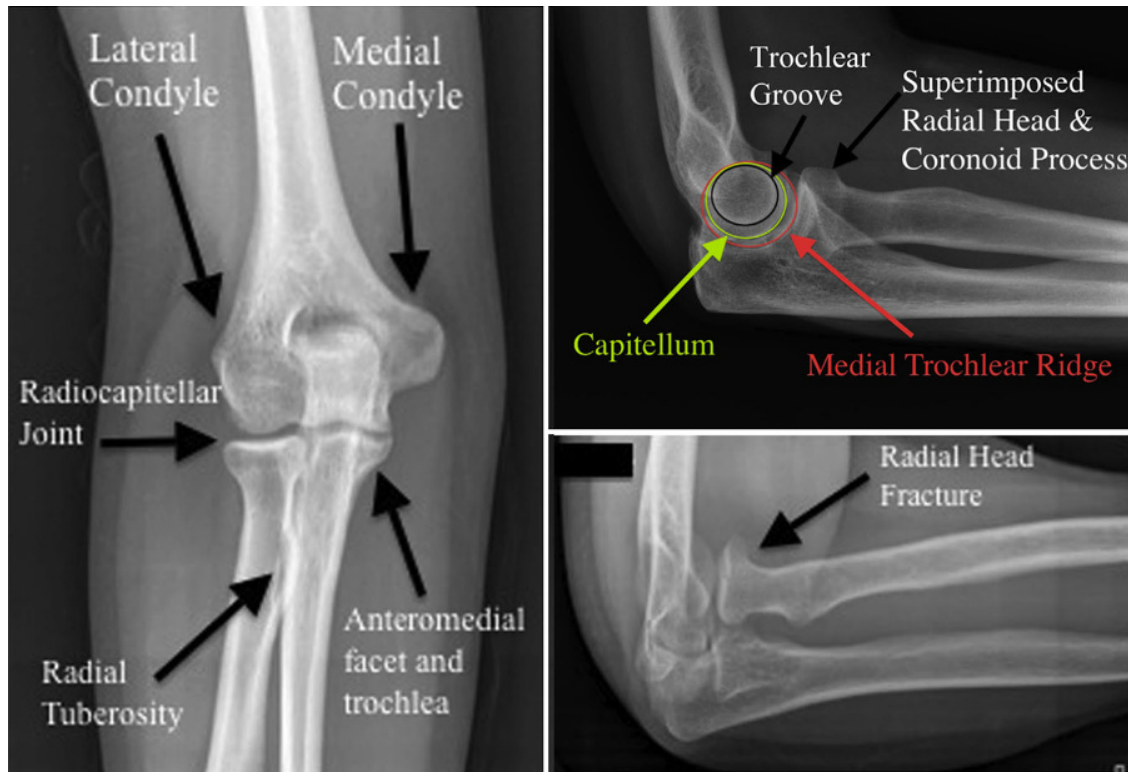

Fig. $2 \Delta$ Radiographic evaluation for radial head fractures. a Anteroposterior, b lateral, and c radiocapitellar views of the elbow. (With kind permission from [29])

tremities should be obtained if the physical examination warrants this. Pain on palpation of the forearm or distal radial ulnar joint (DRUJ) raises concern for Essex-Lopresti type injuries (radial head fracture, interosseous membrane injury, and DRUJ injury) where the radial head is the only structure preventing proximal migration of the radius [1].

Computed tomography (CT) of the elbow with three-dimensional (3D) reconstructions can be obtained to better delineate the fracture pattern and as-

\section{Classification}

The Mason classification with modifications by Hotchkiss, Johnston, Broberg, and Morrey is the most widely used classification system (• Fig. 3; [9]). Type I radial head fractures are nondisplaced or displaced less than $2 \mathrm{~mm}$. Type II fractures are displaced more than $2 \mathrm{~mm}$ or have a fragment size greater than $30 \%$ of the articular surface and may block mechanical motion. Type III fractures are comminuted. Type IV fractures are associated with an elbow dislocation. Despite its widespread use, the Mason classification has poor-to-moderate intra- and interobserver reliability; however, the associated modifications and use of $\mathrm{CT}$ and MRI can significantly improve reliability $[1,3,10]$.

An additional classification system that is primarily used for research purposes is the $\mathrm{AO}$ classification of proximal radius fractures. Fractures of the proximal radius are coded as $2 \mathrm{R} 1$. 2R1A describes extra-articular fractures, 2R1B describes partial articular fractures, and 2R1C describes complete articular fractures. Further numbers can be added to denote the amount of comminution present. 


\section{Treatment}

\section{Mason I}

There is agreement that for Mason I fractures, nonoperative treatment results in excellent outcomes and is the treatment of choice $[1,7,11]$. Successful nonoperative treatment requires early mobilization of the elbow to avoid stiffness. In a systematic review of Mason I fractures, a grade $\mathrm{A}$ recommendation was made for nonoperative treatment consisting of $48 \mathrm{~h}$ of sling immobilization followed by an aggressive mobilization protocol; the authors found that the 48-h immobilization avoided increased pain seen with immediate mobilization and reduced the stiffness seen with longer immobilization [7].

\section{》) Successful nonoperative treatment requires early mobilization of the elbow}

Traditionally, physical therapy is part of nonoperative treatment protocols. However, Egol et al. reported better outcomes with the use of a home exercise program compared with formal biweekly physical therapy [12]. The home exercise program from this study involved active forearm and elbow stretches, and exercises for wrist flexion and elbow pronation/supination all performed twice daily [12]. Eliminating biweekly physical therapy saves time, travel, and money for patients [12]. Especially for young, active patients who should be able to comply, we suggest using a self-directed home exercise program due to the aforementioned benefits.

\section{Mason II}

There is considerable debate over the ideal treatment of Mason II fractures. A mechanical block to rotation on examination is the only absolute indication for surgery $[1,13]$. While pooled data show that there may be benefits for open reduction internal fixation (ORIF), most studies show that outcomes following nonoperative treatment for type II fractures are very good and there is a lower risk of

Obere Extremität 2020 · 15:251-259 https://doi.org/10.1007/s11678-020-00605-w

(c) The Author(s) 2020

\section{G. Larsen · M. J. Fitzgerald · A. S. Greenberg}

\section{Radial head fractures in young, active patients}

\section{Abstract}

The radial head is an important stabilizer of the elbow joint. Radial head fractures are commonly associated with additional injuries to the ligamentous structures of the elbow and can significantly compromise elbow stability. Young patients with radial head fractures are more likely to be male and present after a high-energy mechanism of injury. While not perfect, the Mason classification is the most commonly used classification system and can help to guide the management of radial head fractures. Type I fractures are nondisplaced or minimally displaced (less than $2 \mathrm{~mm}$ ) and are treated nonoperatively with early mobilization. Type II fractures, which are displaced $2-5 \mathrm{~mm}$, can be treated nonoperatively or with open reduction and internal fixation (ORIF). Type III fractures are comminuted and are most often treated with ORIF or with radial head arthroplasty (RHA). Treatment of fractures with an associated elbow dislocation (Mason type IV) is also with ORIF or RHA depending on the degree of comminution. For all of these injuries, assessment and treatment of associated ligamentous injuries are necessary in conjunction with treatment of the bony injury. Despite a significant body of literature available on radial head fractures, there is controversy regarding the optimal management of type II, III, and IV fractures, especially in young, active patients. Common complications following radial head fractures include stiffness, instability, and posttraumatic osteoarthritis; as such, these injuries can lead to significant disability in young, active patients if not managed appropriately.

\section{Keywords}

Elbow - Nonoperative treatment - Open fracture reduction - Radius fractures . Arthroplasty

\section{Radiusköpfchenfrakturen bei jungen, aktiven Patienten}

\section{Zusammenfassung}

Das Radiusköpfchen stellt einen wichtigen Stabilisierungsfaktor des Ellenbogengelenks dar. Radiusköpfchenfrakturen gehen häufig mit zusätzlichen Verletzungen der ligamentären Strukturen des Ellenbogens einher und können die Ellenbogenstabilität erheblich beeinträchtigen. Bei jungen Patienten mit Radiusköpfchenfrakturen handelt es sich eher um männliche Patienten, die ein Hochenergietrauma erlitten haben. Die Mason-Klassifikation ist zwar nicht perfekt, aber das am meisten verbreitete Klassifikationssystem und kann zur Auswahl der geeigneten Versorgung von Radiusköpfchenfrakturen beitragen. Typ-I-Frakturen sind nichtdisloziert oder minimal disloziert (weniger als $2 \mathrm{~mm}$ ) und werden nichtoperativ mit Frühmobilisation behandelt. Typ-IIFrakturen sind 2-5 mm disloziert und können nichtoperativ oder mittels offener Reposition und interner Fixation (ORIF) versorgt werden. Typ-III-Frakturen sind Trümmerfrakturen und werden meist mittels ORIF oder Radiusköpfchenarthroplastik (RHA) behandelt. Die Therapie von Frakturen mit einer begleitenden Ellenbogendislokation
(Mason-Typ IV) erfolgt ebenfalls mittels ORIF oder RHA, je nach Ausmaß der Zertrümmerung. Bei all diesen Läsionen ist die Untersuchung und Behandlung begleitender ligamentärer Verletzungen in Zusammenhang mit der Therapie der knöchernen Verletzung erforderlich. Obwohl es einen wesentlichen Bestand an Literatur zur Radiusköpfchenfraktur gibt, besteht eine Kontroverse in Bezug auf die optimale Behandlung der Frakturen von Typ II, III und IV, insbesondere bei jungen, aktiven Patienten. Zu den häufigen Komplikationen nach Radiusköpfchenfraktur gehörten Steifheit, Instabilität und posttraumatische Arthrose; diese Läsionen können schon für sich genommen zu einer wesentlichen Behinderung junger, aktiver Patienten führen, wenn sie nicht in geeigneter Weise behandelt werden.

\section{Schlüsselwörter}

Ellenbogen · Nichtoperative Behandlung . Offene Frakturreposition - Radiusfrakturen . Arthroplastik 


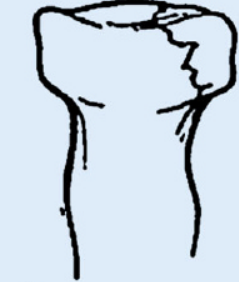

a
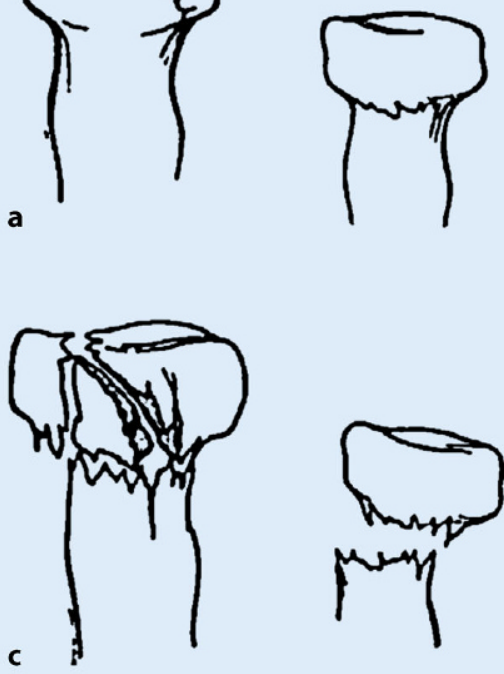

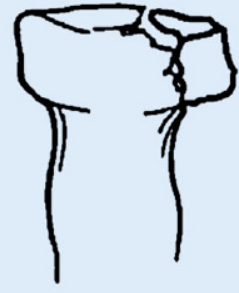

b

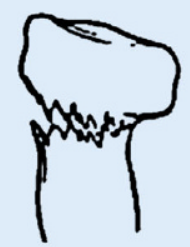

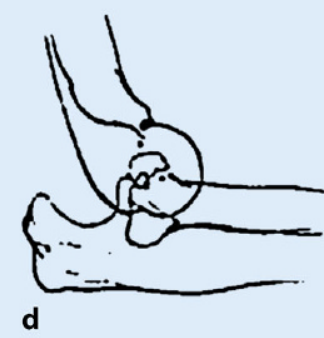

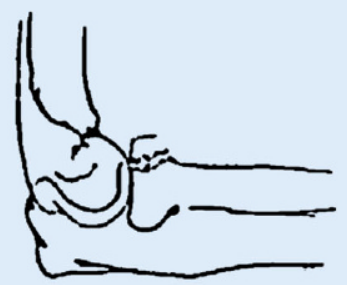

d
Fig. $\mathbf{3}<$ Mason classification. a Type I: nondisplaced. b Type II: partial articular fractures displaced 2-5 mm. cType Ill: comminuted fractures. d Type IV: fracture with elbow dislocation. (With kind permission from [30])
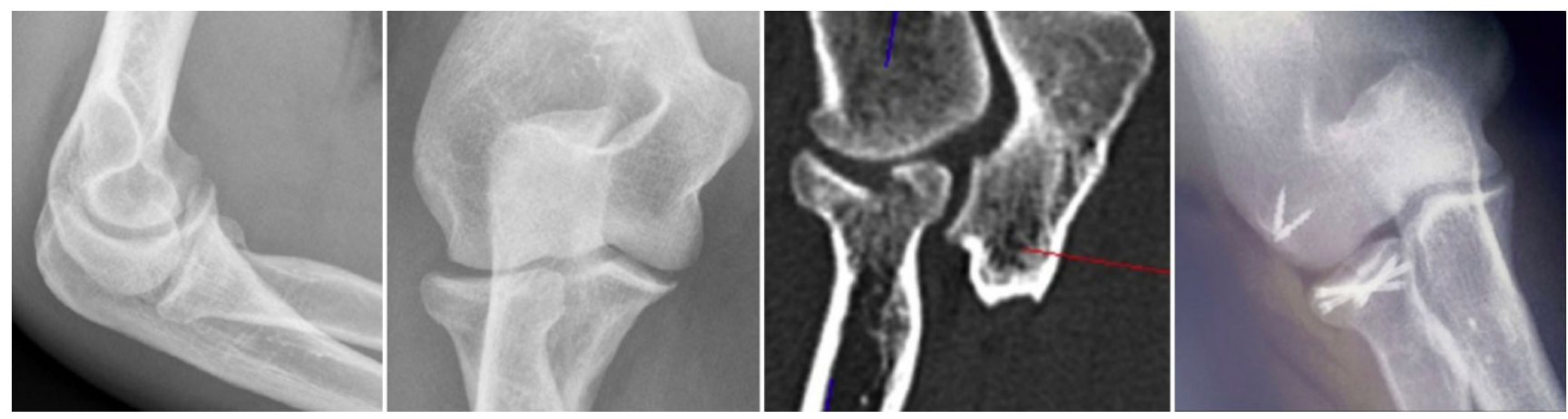

Fig. $4 \Delta$ Mason II radial head fracture treated with open reduction internal fixation (ORIF). Left to right: Lateral and anteroposterior radiographs. Computed tomography scan shows the articular step-off better. ORIF of the fracture along with lateral ulnar collateral ligament repair was performed. (With kind permission from [1])

complications than with ORIF $[11,13$, 14]. The main concern with nonoperative management is that there may be an increased risk of development of arthritic changes at the radiocapitellar joint with the over 2-mm articular step-off [1].

In the only series to evaluate a cohort of young athletes with type II radial head fractures, good or excellent outcomes were found for nonoperative treatment with a mean follow-up of 3 years and all 52 athletes returned to high-demand sports activity at an average of 48 days [15]. The authors found at final follow-up that there was radiographic evidence of degenerative changes of the radiocapitellar joint in $11.5 \%$ of patients [15]. Regardless, this study demonstrates that for young, athletic patients with type II frac- tures, nonoperative treatment is a viable option that allows for quick, reliable return to activity.

Given the lack of a consensus regarding the superiority of ORIF or nonoperative treatment for type II fractures, shared decision-making with the patient is important. The potential increased risk of degenerative changes and reduced longterm function may influence the young, active patient to pursue operative treatment (• Fig.4). However, given that nonoperative management reliably produces good short- to mid-term outcomes and a quick return to activity, it remains a safe, reproducible, and often attractive option.

\section{Mason III-IV}

Type III radial head fractures require surgery; however, there is controversy regarding the decision to attempt ORIF in an effort to save the native radial head, versus replacing the radial head, especially in younger patients. Owing to complications of secondary displacement, non-union, and avascular necrosis reported with ORIF of comminuted fractures, the standard of care is to perform radial head arthroplasty (RHA) for fractures with more than three fragments (• Fig. 5; $[1,16]$ ). The concern with RHA in young patients is that the long-term durability of these implants is unknown and there are uncertainties regarding the development of reciprocal degenerative 

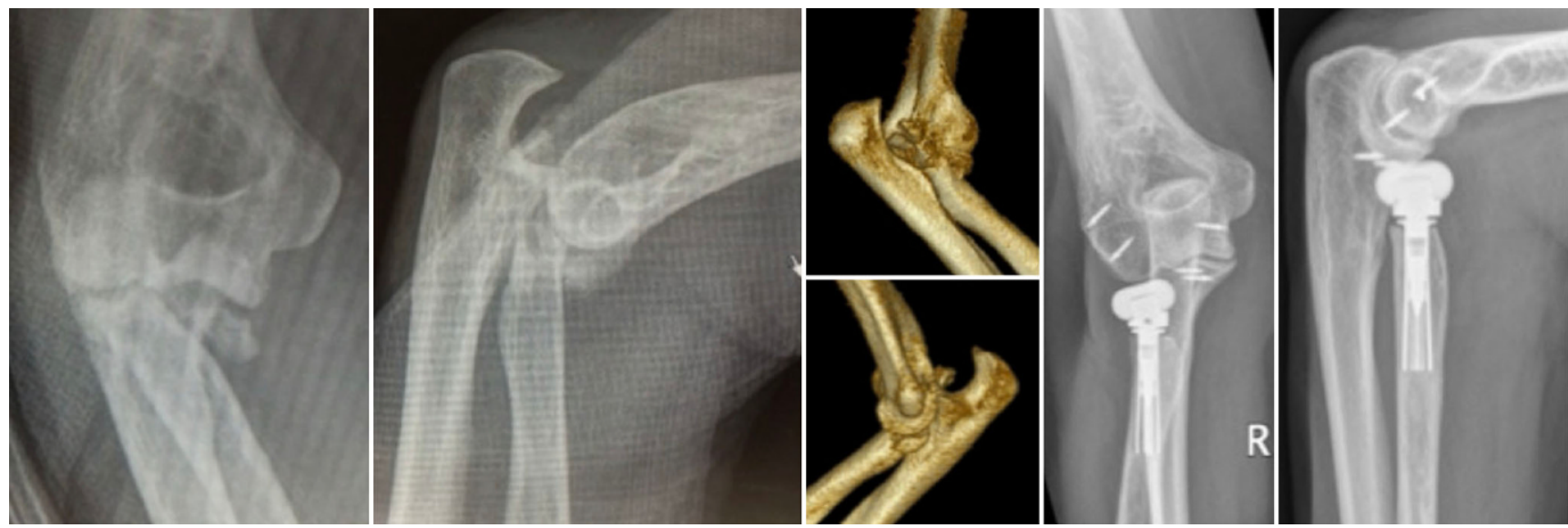

Fig. $5 \Delta$ Mason IV radial head fracture treated with radial head arthroplasty (RHA). Left to right: anteroposterior and lateral radiographs show a comminuted fracture with elbow dislocation. Three-dimensional computed tomography reconstruction shows the comminution. RHA and ligamentous repairs were performed. (With kind permission from [1])
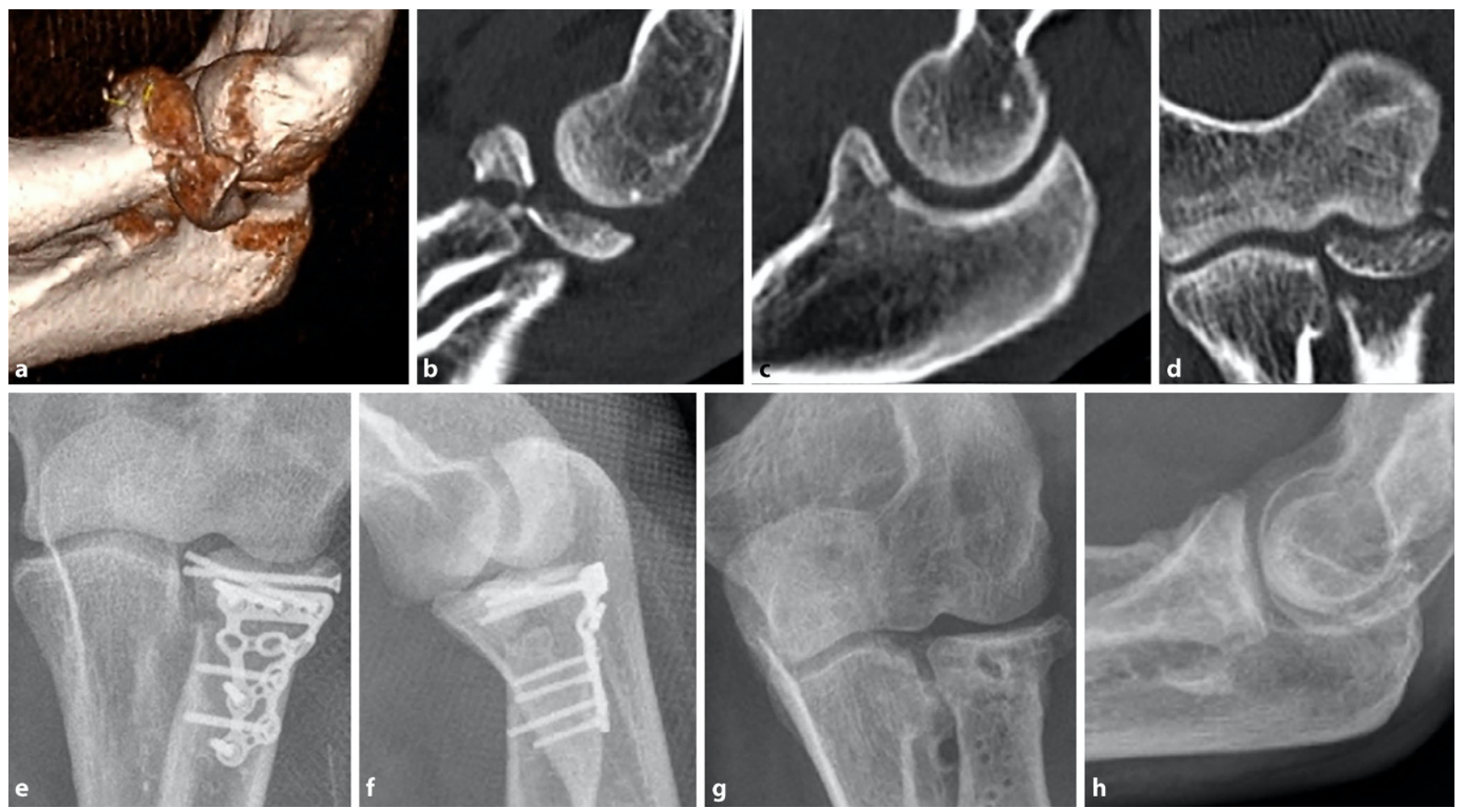

Fig. $6 \Delta$ Mason III fracture treated with open reduction internal fixation (ORIF). a Three-dimensional computed tomography (CT) reconstruction. Sagittal cuts of the CT show articular comminution (b) and coronoid fracture (c). $d$ Cut from coronal CT. e, fORIF with a low-profile, radial head-specific locking plate was performed. $\mathrm{g}$, $\mathrm{h}$ Anteroposterior and lateral radiographs after hardware removal show an intact articular surface. (With kind permission from [16])

changes of the capitellum because the circular implants do not perfectly recreate the elliptical anatomy of the radial head [17]. Radial head excision was previously considered an option; however, due to the risk of proximal migration of the radius and issues with elbow instability, this should not be considered a first-line treatment for active patients
[8]. The management of type IV fractures generally depends on the level of comminution, but these are often comminuted similarly to type III fractures. It is of paramount importance to examine for and address ligamentous instability in all of these high-level fractures, but especially so in type IV fractures due to the associated dislocation. Ligamentous repairs are often necessary in conjunction with treatment of the radial head fracture itself.

With the invention of radial headspecific, low-profile locking plates, there have been multiple recent studies showing that ORIF of highly comminuted fractures can be a viable option ( $\bullet$ Fig. $\mathbf{6}$; $[16,18,19])$. Gruszka et al. reported 
favorable outcomes in 35 patients undergoing ORIF for mostly four- or fivefragment radial head fractures with a $97 \%$ healing rate; however, $38 \%$ of patients required a secondary procedure, of which $32 \%$ included removal of hardware [16]. Similarly, in a study of 20 Mason III and IV fractures following ORIF, 17 patients were highly satisfied and ten achieved unrestricted ROM of the operative extremity [18].

Despite the improvements in technology for ORIF, RHA has increased in popularity over the past decade. There is, however, significant regional variability as a recent study showed that surgeons from North America are ten times more likely to recommend RHA over ORIF for comminuted fractures, compared with European surgeons [20]. The age of the patient has been shown to factor into surgical decision-making as well, with ORIF rates decreasing and RHA rates increasing with age [21].

Among patients of all ages, there remains no consensus regarding ORIF versus RHA for Mason III and IV fractures. In a recent systematic review, Meacher et al. concluded that based on the only two available randomized controlled trials that met their criteria, RHA may have benefits over ORIF, but the evidence is weak [17]. Vannabouathong et al. performed a similar meta-analysis and concluded that RHA resulted in better outcomes and fewer complications at 2 years following surgery [22]. Watters et al. showed equivocal outcome scores and ROM among patients undergoing RHA and ORIF for terrible triad injuries, but at 18 months found that nearly $37 \%$ of the RHA patients had radiographic signs of arthrosis compared with $0 \%$ in the ORIF group [23]. Additionally, Reinhart et al. reported on a large database study of over 7000 patients that showed ORIF was associated with a significantly higher rate of complications and overall cost of care when compared with RHA [24]. The lack of concordance in the findings of these different studies highlights why a consensus has not been reached.

The data for RHA in young, active patients are relatively limited and again there is no consensus. Among patients undergoing RHA for acute traumatic fractures, Duckworth et al. found that at 3 years, younger patients had a higher risk of implant excision [25]. Dunn et al. in a cohort of active military patients with an average age of 31 found excellent subjective outcomes following RHA and reported that 15 of 19 patients were able to return to active duty; however, there was a $47 \%$ complication rate (most common complications: $26 \%$ symptomatic heterotopic ossification, $21 \%$ neurologic sequelae, and $16 \%$ arthrofibrosis) and $63 \%$ of patients were unable to achieve pre-injury functional levels [26]. In a series of active, but older patients (mean age 49), Jung et al. again reported overall favorable subjective outcomes, but found a low return to sport rate of $53 \%$ following RHA and of those who were able to return to sport, $17 \%$ needed to change to a less demanding sport [27]. Lastly, in the only study to date comparing ORIF and RHA in young, active patients, Kusnezov et al. reported twice the complication rate and more reoperations after RHA in active duty military patients. However, there were no differences in functional outcomes and $90 \%$ of patients were able to return to active military duty [4]. Additionally, they found that associated coronoid fractures, LUCL injuries, and type IV injuries increased the risk of complications and reoperations, regardless of the surgical treatment chosen [4]. Ultimately, they concluded that ORIF and RHA are both viable options in young, active patients despite an increased risk of complications with RHA in this population [4].

Given the increased risk of complications, the possibility of capitellar erosion, and uncertainty regarding long-term outcomes of RHA in young, active patients, it seems advantageous to perform ORIF of the radial head if possible. With the availability of radial head-specific, lowprofile locking plates, ORIF may be more likely than in the past to be successful in fractures with increased comminution relative to the conventional teaching of three fragments. However, priority must be given to recreating a stable elbow joint, and thus sometimes RHA will be necessary in this population and the data show that good outcomes can still be achieved.

\section{Postoperative care}

The duration of postoperative immobilization depends on both the strength of fixation and the stability of the elbow. Isolated Mason II fractures that undergo ORIF can be mobilized immediately [1]. More complex injuries can be splinted for up to 2 weeks; however, the splint should be removed intermittently for supervised physical therapy. If residual joint instability persists, or there are ligamentous repairs to protect, use of a hinged elbow brace can be helpful. In grossly unstable injuries, where adequate stability for early joint mobilization cannot be achieved in the OR, the surgeon should consider application of a dynamic external fixator.

Physical therapy is initiated within the first week to regain ROM and strengthen active stabilizers through active and active-assisted exercises. Forearm rotation should be performed with 90 degrees of elbow flexion to protect any collateral ligament repairs, and elbow extension exercises are performed with the forearm rotated appropriately to protect collateral repairs (LUCL protected in pronation, MCL protected in supination) or in neutral if both collaterals were involved [1]. Varus and valgus stress, resistive exercises, and weight-bearing are fully restricted for 6 weeks and are gradually permitted after that based on the surgeon's preference.

\section{》) Physical therapy is initiated within the first week to regain range of motion}

Return-to-play criteria for recreational and/or competitive sports participation are not well-established following surgery for radial head fractures. The operative elbow should be compared with the nonoperative elbow with regard to stability, strength, and ROM and ultimately a joint decision should be made with input from both the patient and the surgeon. Generally, return to play should not be expected earlier than 3 months postoperatively for isolated Mason II fractures after ORIF and no sooner than 6 months for more complex injuries with associated soft tissue repairs. 
Hier steht eine Anzeige.

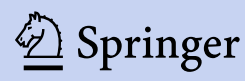




\section{Complications}

Regardless of treatment, the most common complication is stiffness [28]. This is why it is important to work on elbow ROM early in the recovery process. In a large multicenter study, the next most common complications were instability and posttraumatic osteoarthritis, seen in 36.5 and $29.2 \%$ of cases, respectively [28]. As expected, recurrent instability was most common after treatment of type III and IV fractures. A large percentage of the patients who developed osteoarthritis were those with type II fractures treated nonoperatively, which is why it is important to counsel young patients regarding this risk if they are considering nonoperative treatment. Next most likely are complications from hardware including painful hardware, hardware restricting ROM, loss of fixation or hardware failure, and RHA prosthesis failure, dislocation, or loosening.

\section{Practical conclusion}

- Radial head fractures can compromise elbow stability and should be viewed as "osteoligamentous" injuries due to their association with damage to the surrounding soft tissues. Both bony and soft tissue injuries must be addressed to restore stability to the elbow joint.

- Conservative management should be pursued for type I injuries with an emphasis on early range of motion to prevent stiffness.

- Type II fractures can generally be treated with either conservative management or open reduction internal fixation (ORIF), both provide good functional outcomes. However, young patients should be aware that there is potentially an increased risk of posttraumatic osteoarthritis with nonoperative treatment of type II fractures.

- Controversy remains regarding best treatment for Mason III and IV injuries. While good outcomes in young, active patients are achievable with both ORIF and radial head arthroplasty, complication rates appear to be higher for arthroplasty in this population and newer radial head-specific plating systems likely allow for good outcomes with ORIF of fractures that have more fragments than the conventional limit of three.

\section{Corresponding address

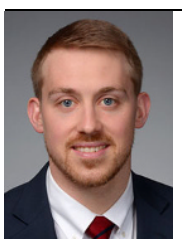 \\ Christopher G. Larsen, MD Department of Orthopaedic Surgery, Northwell Health 270-05 76th Avenue, 11040 New Hyde Park, NY, USA clarsen@northwell.edu}

\section{Compliance with ethical guidelines}

Conflict of interest. A.S. Greenberg is a consultant for Arthrex and Medartis. C.G. Larsen and M.J. Fitzgerald declare that they have no competing interests.

For this article no studies with human participants or animals were performed by any of the authors. All studies performed were in accordance with the ethical standards indicated in each case.

Open Access. This article is licensed under a Creative Commons Attribution 4.0 International License, which permits use, sharing, adaptation, distribution and reproduction in any medium or format, as long as you give appropriate credit to the original author(s) and the source, provide a link to the Creative Commons licence, and indicate if changes were made. The images or other third party material in this article are included in the article's Creative Commons licence, unless indicated otherwise in a credit line to the material. If material is not included in the article's Creative Commons licence and your intended use is not permitted by statutory regulation or exceeds the permitted use, you will need to obtain permission directly from the copyright holder. To view a copy of this licence, visit http://creativecommons.org/licenses/by/4.0/.

\section{References}

1. Burkhart KJ, Wegmann K, Müller LP, Gohlke FE (2015) Fractures of the radial head. Hand Clin 31(4):533-546

2. Duckworth AD, Clement ND, Jenkins PJ, Aitken SA, Court-Brown CM, McQueen MM (2012) The epidemiology of radial head and neck fractures. JHand Surg Am 37(1):112-119

3. Swensen SJ, Tyagi V, Uquillas C, Shakked RJ, Yoon RS, Liporace FA (2019) Maximizing outcomes in the treatment of radial head fractures. J Orthop Traumatol 20(1):15

4. Kusnezov N, Eisenstein E, Dunn JC et al (2018) Operative management of unstable radial head fractures in a young active population. Hand (NY) 13(4):473-480

5. Rhyou IH, Lee JH, Kim KC, Ahn KB, Moon SC, Kim HJ (2017) What injury mechanism and patterns of ligament status are associated with isolated coronoid, isolated radial head, and combined fractures? Clin Orthop Relat Res 475(9):2308-2315 6. Kodde IF, Kaas L, van Es N, Mulder PG, van Dijk CN, Eygendaal D (2015) The effect of trauma and patient related factors on radial head fractures and associated injuries in 440 patients. BMC Musculoskelet Disord 16:135

7. de Muinck Keizer RJ, Walenkamp MM, Goslings JC, Schep NW (2015) Mason type I fractures of the radial head. Orthopedics 38(12):e1147-54

8. Awan H, Goitz R (2017) MRI correlation of radial head fractures and forearm injuries. Hand (N Y) 12(2):145-149

9. Iannuzzi NP, Leopold SS (2012) In brief: the Mason classification of radial head fractures. Clin Orthop Relat Res 470(6):1799-1802

10. Haasters F, Helfen T, Böcker W, Mayr HO, Prall WC, Lenich A (2019) The value of elbow arthroscopy in diagnosing and treatment of radial head fractures. BMC Musculoskelet Disord 20(1):343

11. Duckworth AD, Wickramasinghe NR, Clement ND, Court-Brown CM, McQueen MM (2014) Long-term outcomes of isolated stable radial head fractures. JBone Joint Surg Am 96(20):1716-1723

12. Egol KA, Haglin JM, Lott A, Fisher N, Konda SR (2018) Minimally displaced, isolated radial head and neck fractures do not require formal physical therapy: results of a prospective randomized trial. JBone Joint Surg Am 100(8):648-655

13. Martin DP, Wilt ZT, Cantlon MB, Wang ML (2017) Controversies surrounding the management of the isolated type-II radial-head fracture. JBJS Rev 5(12):e3

14. Yoon A, King GJ, Grewal R (2014) Is ORIF superior to nonoperative treatment in isolated displaced partial articular fractures of the radial head? Clin Orthop Relat Res 472(7):2105-2112

15. Guzzini M, Vadalà A, Agrò A, Di Sanzo V, Pironi D, Redler A et al (2017) Nonsurgical treatment of Mason type II radial head fractures in athletes. A retrospective study. GChir 37(5):200-205

16. Gruszka D, Nowak TE, Tkacz T, Wagner D, Rommens PM (2019) Complex radial head and neck fractures treated with modern locking plate fixation. JShoulder Elbow Surg 28(6):1130-1138

17. Meacher H, Hermena S, Isaac S (2020) Open reduction and internal fixation versus radial head arthroplasty for mason III radial head fractures: appraising the current literature evidence. Cureus 12(4):e7501

18. Crönlein M, Zyskowski M, Beirer M, Imhoff FB, Pförringer D, Sandmann GH et al (2017) Using an anatomically preshaped low-profile locking plate system leads to reliable results in comminuted radial head fractures. Arch Orthop Trauma Surg 137(6):789-795

19. Liu G, Chen E, Xu D, Ma W, Zhou L, Chen J et al (2018) Open reduction and internal fixation with bone grafts for comminuted mason type II radial head fractures. BMC Musculoskelet Disord 19(1):288

20. O'Connor CM, Kortlever J, Vagner GA, Reichel LM, Ring D (2020) Patient and surgeon factors associated with prosthetic replacement rather than with open reduction and internal fixation of a radial head fracture. Hand (N Y). https://doi.org/ $10.1177 / 1558944720918358$

21. Kupperman ES, Kupperman Al, Mitchell SA (2018) Treatment of radial head fractures and need for revision procedures at 1 and 2 years. J Hand Surg Am 43(3):241-247

22. Vannabouathong $C$, Akhter S, Athwal GS, Moro J, Bhandari M (2019) Interventions for displaced radial head fractures: network meta-analysis 
of randomized trials. J Shoulder Elbow Surg 28(3):578-586

23. Watters TS, Garrigues GE, Ring D, Ruch DS (2014) Fixation versus replacement of radial head in terrible triad: is there a difference in elbow stability and prognosis? Clin Orthop Relat Res 472(7):2128-2135

24. Reinhardt D, Toby EB, Brubacher J (2019) Reoperation rates and costs of radial head arthroplasty versus open reduction and internal fixation of radial head and neck fractures: a retrospective database study. Hand (N Y). https://doi.org/10. 1177/1558944719837691

25. Duckworth AD, Wickramasinghe NR, Clement ND, Court-Brown CM, McQueen MM (2014) Radial head replacement for acute complex fractures: what are the rate and risks factors for revision or removal? Clin Orthop Relat Res 472(7):2136-2143

26. Dunn JC, Kusnezov NA, Koehler LR, Eisenstein ED, Kilcoyne KG, Orr JD et al (2017) Radial head arthroplasty in the active duty military service member with minimum 2-year follow-up. J Hand Surg Am 42(8):660.e1-660.e7

27. Jung $M$, Groetzner-Schmidt $C$, Porschke $F$, Grützner PA, Guehring T, Schnetzke M (2019) Low return-to-sports rate after elbow injury and treatment with radial head arthroplasty. JShoulder Elbow Surg 28(8):1441-1448

28. Hackl M, Wegmann $K$, Hollinger B, El-Zayat BF, SeyboldD, Gühring Tetal (2019) Surgical revision of radial head fractures: a multicenter retrospective analysis of 466 cases. J Shoulder Elbow Surg 28(8):1457-1467

29. Crosby NE, Greenberg JA (2014) Radiographic evaluation of the elbow. J Hand Surg Am 39(7):1408-1414

30. Peyronnet A, Marc C, Lancigu R, Rony L, Cronier P, Hubert $L$ (2017) Percutaneous reduction of proximal radius fracture in adults. A 12-case series. Orthop Traumatol Surg Res 103(2):315-318 